\section{Influence of Diurnal Temperature on Nutrient Release Patterns of Three Polymer-coated Fertilizers}

\author{
Chad E. Husby ${ }^{1}$, Alexander X. Niemiera ${ }^{2}$, J. Roger Harris ${ }^{2}$, and \\ Robert D. Wright ${ }^{3}$ \\ Department of Horticulture, Virginia Tech, Blacksburg, VA 24061
}

Additional index words. nutrition, container-grown, fertilizers, nursery crops, controlledrelease fertilizers

\begin{abstract}
This study was conducted to determine the effects of temperature on nutrient release patterns of three polymer-coated fertilizers (PCFs), each using a different coating technology: Osmocote Plus 15N-3.93P-9.96K, Polyon 18N-2.62P-9.96K, and Nutricote 18N-2.62P-6.64K. Each fertilizer was placed in a sand-filled column and leached with distilled water at $\approx 100 \mathrm{~mL} \cdot \mathrm{h}^{-1}$, while being subjected to a simulated diurnal container temperature change from 20 to $40{ }^{\circ} \mathrm{C}$ and back to $20^{\circ} \mathrm{C}$ over a period of 20 hours. Column leachate was collected hourly and measured for soluble salts and $\mathrm{NO}_{3}-\mathrm{N}$ and $\mathrm{NH}_{4}-\mathrm{N}$ content. For all fertilizers, nutrient release increased and decreased with the respective increase and decrease in temperature. Nutrient release patterns of the three fertilizers differed, with Osmocote Plus showing the greatest overall change in nutrient release between 20 and $40{ }^{\circ} \mathrm{C}$, and Nutricote the least.
\end{abstract}

Controlled-release fertilizers (CRFs) are used extensively in container-grown plant production. A fundamental motivation for the development of CRF has been the goal of delivering nutrients to plants at rates that approximate plant demand over an extended period (Goertz, 1993; Oertli, 1980). Fertilizers with this capacity can have many benefits to the nursery industry, such as greater nutrient use efficiency, better plant growth and quality, lower labor and management costs, and reduced fertilizer leaching and runoff pollution (Goertz, 1993; Oertli, 1980; Shaviv and Mikkelsen, 1993).

The most widely used CRFs in container nursery plant production are polymer-coated fertilizers (PCFs). PCFs consist of soluble fertilizer encapsulated in a polymer coating. Each fertilizer capsule is called a prill. PCFs release nutrients through a semipermeable membrane formed by the polymer coating (Bunt, 1988; Goertz, 1993). Water vapor diffuses into the prill, condenses, and then dissolves some of the fertilizer salts inside the prill (Bunt, 1988; Goertz, 1993). The resulting fertilizer solution is thought to be released either via diffusion (Bunt, 1988; Goertz, 1993) or the forcing of nutrient solution out of membrane by hydrostatic pressure (Kochba et al., 1990; Oertli, 1980).

Polymer-coated fertilizer nutrient release is primarily influenced by temperature and time (Hinklenton and Cairns, 1992; Lamont et al., 1987; Oertli and Lunt 1962a, 1962b).

Received for publication 11 Jan. 2002. Accepted for publication 29 July 2002. This paper is a portion of a thesis submitted by Chad E. Husby in partial fulfillment of the MS degree requirements at Virginia Tech. Mention of brand names is for informational purposes only and does not imply its approval to the exclusion of other products that may also be suitable.

${ }^{1}$ Graduate Student.

${ }^{2}$ Associate Professor

${ }^{3}$ Professor.
An increase in temperature generally causes an increase in nutrient release rate (Tamimi et al., 1983). PCF manufacturers categorize their products by longevity of nutrient release which is based upon the length of time necessary for the fertilizer to release a high percentage $(\approx 80 \%)$ of its contents at a given temperature (e.g., $21^{\circ} \mathrm{C}$ ). However, several investigators have questioned the adequacy of longevity ratings for evaluating PCF performance. For example, Meadows and Fuller (1983) found that nitrogen release from 8- to 9-month and 12- to 14-month rated PCFs dropped below satisfactory levels after only 4 months. In addition, Cabrera (1997) found that different PCFs with 8-to 9-month longevity ratings have different $\mathrm{N}$ release patterns as indicated by nutrient leaching from pots during a growing season in greenhouse conditions.

Previous studies have evaluated temperature effects based upon incubations at a constant temperature for many weeks (Lamont et al., 1987; Tamimi et al., 1983). However, studies have shown that daily nursery container temperatures often fluctuate widely. Ingram (1981) and Ingram et al. (1989) found that substrate temperatures in the center of a rigid black plastic nursery container in Florida increased from 21 to $40^{\circ} \mathrm{C}$ or more in as little as 6 to $9 \mathrm{~h}$ when exposed to the sun. The impact of short-term diurnal temperature fluctuations in containers on PCF nutrient release has not been investigated. The objective of this study was to investigate the effects of short-term (diurnal) temperature differences (under laboratory conditions) on patterns of nutrient release for three PCFs each with a different coating technology.

\section{Materials and Methods}

Each of the three PCFs used in this experiment was produced by a different manufac- turer, each of which uses a different coating technology (Goertz, 1993). The PCF types used $(100 \%$ coated material) were Osmocote Plus 15N-3.93P-9.96K (Scotts-Sierra Horticultural Products, Marysville, Ohio), Polyon 18N-2.62P-9.96K (Pursell Technologies, Sylacauga, Ala.), and Nutricote $18 \mathrm{~N}-2.62 \mathrm{P}-6.64 \mathrm{~K}$ (Chisso-Asahi Fertilizer Co., Tokyo). Osmocote Plus $15 \mathrm{~N}-3.93 \mathrm{P}-9.96 \mathrm{~K}$ had a longevity rating of 8-9 months $\left(24{ }^{\circ} \mathrm{C}\right)$, while Polyon $18 \mathrm{~N}-2.62 \mathrm{P}-9.96 \mathrm{~K}$ and Nutricote $18 \mathrm{~N}-2.62 \mathrm{P}$ $6.64 \mathrm{~K}$ each had a longevity rating of 9 months at 26.7 and $25{ }^{\circ} \mathrm{C}$, respectively. Furthermore, both Osmocote Plus 15N-3.93P-9.96K and Nutricote $18 \mathrm{~N}-2.62 \mathrm{P}-6.64 \mathrm{~K}$ contained micronutrients ( $\mathrm{B}, \mathrm{Cu}, \mathrm{Fe}, \mathrm{Mn}, \mathrm{Mo}$, and $\mathrm{Zn})$ in addition to $\mathrm{N}, \mathrm{P}$, and $\mathrm{K}$. The percent $\mathrm{N}_{\text {as }} \mathrm{NH}_{4}-\mathrm{N}$ and $\mathrm{NO}_{3}-\mathrm{N}$, respectively, was $7 \%$ and $8 \%$ for Osmocote Plus, $8.5 \%$ and $8.6 \%$ for Polyon, and $8.6 \%$ and $9.4 \%$ for Nutricote.

Fourteen grams each of the three PCFs and $100 \mathrm{~mL}$ distilled water were put into $125-\mathrm{mL}$ Erlenmeyer flasks. There were two flasks of each of the three fertilizer types. Flasks were placed in a randomized arrangement in a water bath at $40{ }^{\circ} \mathrm{C}$. Bath temperature was maintained with a temperature controller and circulator. Flasks were incubated until the average release of $\mathrm{NO}_{3}-\mathrm{N}$ for Osmocote Plus (using the manufacturers' stated formulation to compute the initial amount of $\mathrm{NO}_{3}-\mathrm{N}$ ) approached $33 \%$, which occurred after 3 weeks of incubation. The purpose of this 3 -week high temperature period was to reduce the possible contribution of initially very high release rates (characteristic of many PCFs) to subsequent release rate measurements. The percent release of the other two products was not determined for the 3-week period. Fertilizer prills (entire 14-g sample) were then removed from the flasks and placed in empty columns to $\approx 1 \mathrm{~cm}$ of top. Dry, acid-washed sand was then added to the top of the column until the sand filled the spaces between prills and covered the prills slightly. Column length and diameter were $\approx 15.5$ and $1.5 \mathrm{~cm}$, respectively, and some columns were lengthened to $20 \mathrm{~cm}$ to accommodate swelling of prills. Cotton fiber was placed in the bottom of each column before filling to prevent the escape of sand. A thermocouple was placed in one of the columns central to the fertilizer prills.

Three columns, each filled with one of the three PCFs, were then attached to the side of a 7.6-L glass jar that was inside a Styrofoam box for insulation. The glass jar was filled with distilled water and the water temperature was controlled by an MTP-5 Microprocessor Temperature Programmer (Neslab Instruments, Etobicoke, Ont.) and a Digital Exatrol heater and temperature sensor (Neslab Instruments, Etobicoke, Ont.). A loop of flexible tubing attached to the intake and outflow nozzles of a Lauda RM6 cooling bath (Brinkmann Instruments, Wesbury, N.Y.) was also placed in the glass jar bath to help control the temperature. Tygon flexible plastic tubing (Norton Performance Plastics, Akron, Ohio) was fitted to the bottom of each column and the tubing emerged through a hole in the bottom of the Styrofoam box. The end of each 
tube was positioned over a set of fraction collectors using 18-mm-diameter test tubes. Columns were then further insulated by packing polyester fiber between the columns and the Styrofoam container wall. After the columns were attached to the bath, distilled water from the bath was pumped (at $\approx 90$ to $100 \mathrm{~mL} \cdot \mathrm{h}^{-1}$ ) into each column by a peristaltic cassette pump (Manostat Corp., New York) through separate flexible Tygon tubes. Leachate from each column was collected separately in test tubes on fraction collectors $(\approx 25 \mathrm{~mL}$ leachate/tube). The bath temperature was then adjusted so that the column temperature was $\approx 20{ }^{\circ} \mathrm{C}$. The electrical conductivity (EC) of the leachate was measured intermittently to determine when nutrient release had stabilized for each of the fertilizers. Once nutrient release stabilized at $20^{\circ} \mathrm{C}$, columns were subjected to a gradual increase $\left(\approx 2.4{ }^{\circ} \mathrm{C} / \mathrm{h}\right)$ to $40{ }^{\circ} \mathrm{C}$ and a subsequent decrease to $20^{\circ} \mathrm{C}$, which simulated a temperature regime that has been found to occur in outdoor nursery containers (Ingram, 1981). The $20^{\circ} \mathrm{C}$ temperature was then maintained for another hour. Leachate from each column was collected for each of the $20 \mathrm{~h}$ of the experiment and analyzed for EC, and $\mathrm{NO}_{3}-\mathrm{N}$ and $\mathrm{NH}_{4}-\mathrm{N}$ concentrations.

The EC of nutrient solutions was measured with a CDM83 Conductivity Meter (RadiometerCopenhagen, Copenhagen, Denmark). The EC was converted to about $\mathrm{mg} \cdot \mathrm{L}^{-1}$ soluble salts by multiplying EC readings $\left(\mathrm{dS} \cdot \mathrm{m}^{-1}\right)$ by 700 (Bunt, 1988). $\mathrm{NO}_{3}-\mathrm{N}$ concentration was measured with a Cardy Nitrate Meter (Horiba, Japan). $\mathrm{NH}_{4}-\mathrm{N}$ concentration was measured with an ammonia-selective electrode (HNU Systems, Newton, Mass.) and an Orion Research Microprocessor Ionalyzer/901 (Orion Research, Boston).

The experiment was then repeated for a second replication of three columns containing the three different PCFs. The experimental design was completely randomized with repeated measures. There were two replications of each of the three fertilizers. Data were analyzed using SAS (version 6.12, SAS Institute, Cary, N.C.) PROC MIXED using AR(1) autocorrelation for the repeated measures. Data were transformed using natural $\log$ transformation.

\section{Results and Discussion}

For all fertilizers, nutrient release increased and decreased with the respective increase and decrease in temperature (Fig. 1) with a remarkably symmetrical pattern. For all nutrient release parameters measured (soluble salts, $\mathrm{NO}_{3}-\mathrm{N}$, and $\mathrm{NH}_{4}-\mathrm{N}$ ), there was a significant product $\times$ temperature interaction $(P$-values: 0.0001 for soluble salts; 0.0046 for $\mathrm{NO}_{3}-\mathrm{N}$; and 0.0001 for $\left.\mathrm{NH}_{4}-\mathrm{N}\right)$. At the lower temperature range $\left(20\right.$ to $\left.35^{\circ} \mathrm{C}\right)$ Osmocote released the least, Nutricote the most, with Polyon being intermediate. At the higher temperature range (35 to $40{ }^{\circ} \mathrm{C}$ ), Osmocote released the most, Nutricote the least, with Polyon again being intermediate. Increases in nitrate (between 20 and $40{ }^{\circ} \mathrm{C}$ ) were largest for Osmocote Plus $(4123 \%)$ and smallest for Nutricote $(1277 \%)$

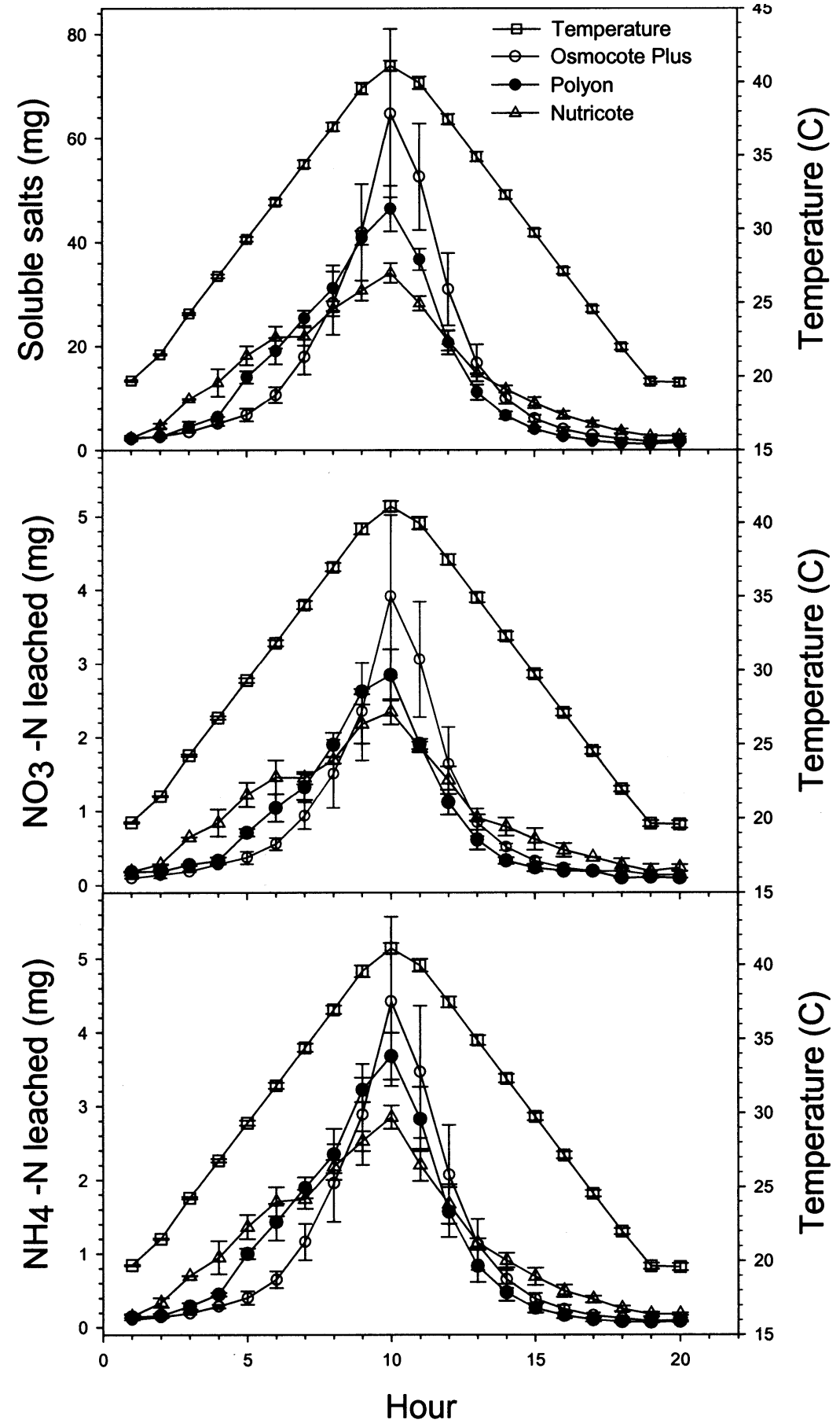

Fig. 1. Soluble salt, $\mathrm{NO}_{3}-\mathrm{N}$, and $\mathrm{NH}_{4}-\mathrm{N}$ release of Osmocote Plus (O), Polyon $(\bullet)$, and Nutricote $(\triangle)$ controlled-release fertilizers in sand columns subjected to simulated diurnal temperature changes $(\square)$. Bars represent SE mean of untransformed data. $\mathrm{N}=2$.

with Polyon being intermediate at $1592 \%$ (data not shown).

Our results support a well-established fact that increasing substrate temperature surrounding PCFs increases the rate of nutrient release from the prills (Hinklenton and Cairns, 1992; Lamont et al., 1987; Oertli and Lunt, 1962a, 1962b; Tamimi et al., 1983). The former studies, however, evaluated the effects of constant temperature over many weeks. Our results are more descriptive showing a more dynamic, diurnal release response of PCFs to temperature.
If these laboratory findings are indicative of PCF performance in nursery conditions, then daily container temperature changes may have rapid effects on container nutrient levels as well as on nutrient release longevity of PCFs. The fate of nutrients released from PCFs during times of high substrate temperature $(>20$ ${ }^{\circ} \mathrm{C}$ ) has not been investigated but the potential avenues for released nutrients are: absorption by roots (to sustain growth or luxury consumption), adsorption by the substrate, and leaching from the substrate during irrigation or rainfall events. To what degree these avenues constitute 
the fate of nutrients released as temperatures rise is unknown, and is likely to depend on environmental conditions, plant size and irrigation practices. However, since high substrate temperatures $\left(>20^{\circ} \mathrm{C}\right)$ occur almost daily during the summer and nutrients are very leachable from a soilless substrate (Foster et al., 1983), and in view that most container-grown crops are irrigated at least once a day, the potential for nutrients to be leached is relatively high unless there are concomitant increases in plant nutrient uptake with diurnal increases in temperature and nutrient release. Optimal conditions for plant nutrient uptake should be maintained during the time of accelerated nutrient release. This approach could improve nutrient-use efficiency by reducing the amount leached from the container during the next irrigation event. If plants were irrigated in such a manner to prevent afternoon moisture stress, then plants would be more likely to benefit from the accelerated mid-day nutrient release. Future work will focus on this question.

To what extent our results favor one product over another is not clear since all three products have been shown to produce comparable growth when tested against one another in Blacksburg, Va. (unpublished data). One might be led to conclude that products that release more at the higher temperatures are less desirable than those whose release is less affected by temperature since the former products longevity of release could be shortened. However, the process of nutrient uptake by plants - and ultimately plant growth - in response to fluctuating substrate nutrient levels is likely somewhat complicated given a plant's capacity to respond to both diurnal changes in nutrient availability as well as long term changes in availability as each product differentially expends its capacity for nutrient release.

\section{Literature Cited}

Bunt, A.C. 1988. Media and mixes for containe grown plants. Unwin Hyman, London.

Cabrera, R.I. 1997. Comparative evaluation of nitrogen release patterns from controlled release fertilizers by nitrogen leaching analysis. HortScience 32:669-673.

Foster, W.J., R.D. Wright, M.M. Alley, and T.H. Yeager. 1983. Ammonium adsorption on a pinebark growing medium. J. Amer. Soc. Hort. Soc 108:548-551.

Goertz, H.M. 1993. Controlled release technology, p. 251-274. In: M. Howe-Grant (ed.). Kirk-Othmer encyclopedia of chemical technology. Vol. 7.4th ed. Wiley, New York.

Hinklenton, P.R. and K.G. Cairns. 1992. Solubility and application rate of controlled release fertilizer affect growth and nutrient uptake in containerized woody landscape plants. J.Amer. Soc. Hort. Sci. 117:578-583.

Ingram, D.L. 1981. Characterization of temperature fluctuations and woody plant growth in white poly bags and conventional black containers. HortScience 16:762-763.

Ingram, D.L., C. Martin, and J. Ruter. 1989. Effects of heat stress on container-grown plants.
Combined Proc. - Intl. Plant Propagators' Soc. 39:348-352.

Kochba, M., S. Gambash, and Y. Avnimelech. 1990. Studies on slow release fertilizers: 1. Effects of temperature, soil moisture, and water vapor pressure. Soil Sci. 149: 339-343.

Lamont, G.P., R.J. Worrall, and M.A. O'Connell. 1987. The effects of temperature and time on the solubility of resin-coated controlled-release fertilizers under laboratory and field conditions. Sci. Hort. 32:265-273.

Meadows, W.A. and D.L. Fuller. 1983. Nitrogen and potassium release patterns of five formulations of Osmocote fertilizers and two micronutrient mixes for container grown woody ornamentals. SNA Nursery Res. J. 9(1):28-34.

Oertli, J.J. 1980. Controlled-release fertilizers. Fert. Res. 1:103-123.

Oertli, J.J. and O.R. Lunt. 1962a. Controlled release of fertilizer minerals by incapsulating membranes: I. Factors influencing the rate of release. Soil Sci. Soc. Amer. Proc. 26:579-583.

Oertli, J.J. and O.R. Lunt. 1962b. Controlled release of fertilizer minerals by incapsulating membranes: II. Efficiency of recovery, influence of soil moisture, mode of application, and other considerations related to use. Soil Sci. Soc. Amer. Proc. 26:584-587.

Shaviv, A. and R.L. Mikkelson. 1993. Controlledrelease fertilizers to increase efficiency of nutrient use and minimize environmental degradation $-\mathrm{A}$ review. Fert. Res. 35:1-12.

Tamimi, Y.N., D.T. Matsuyama, and C.L. Robbins. 1983. Release of nutrients from resin coated fertilizers as affected by temperature and time. Res. Ext. Ser., College Trop. Agr. and Human Resources, Univ. of Hawaii 037:59-73. 